\title{
RISADA PEGA: A Mnemonic Method in Portuguese for Alarm Criteria in Emergency Headaches
}

\author{
Hilton Mariano da Silva Júnior ${ }^{(D)}$, Larissa Volpini Cardoso \\ Pontifícia Universidade Católica de Campinas, Campinas, São Paulo, Brasil.

\section{Introduction} \\ We present the first mnemonic method in Portuguese, "RISADA PEGA", for alarm criteria in emergency headaches in \\ order to facilitate their identification and diagnosis. A search was made through different databases for a mnemonic \\ method regarding alarm criteria in emergency headaches, and methods in English and Spanish were found, but there \\ was no mention of one written in Portuguese.
}

\author{
Result \\ With that in mind, the method "RISADA PEGA" ("laughter spreads", in English) was created: \\ R - Repentina / (Sudden) \\ I - Início depois dos 50 anos / (onset in a patient older than 50) \\ $\mathrm{S}$ - Sinais e/ou sintomas de doenças sistêmicas ou neurológicas / (Signs and/or symptoms of systemic or neurologic \\ diseases) \\ A - Anormalidades no exame neurológico/(abnormalities upon neurologic examination) \\ D - Depressão da imunidade (AIDS, Câncer)/Depressed immunity (HIV or cancer) A - Antecedentes: doenças que \\ podem acometer o SNC; número de vindas ao PS, \\ história familiar de cefaleia)/(Prior conditions: diseases affecting the central nervous system; number of visits to the \\ health center, history of headache in the family) \\ P - Padrão alterado (mudança no padrão anterior da cefaleia) / (change in headache pattern) \\ E - Esforço / (exertion) \\ G - Gravidez / (pregnancy) \\ A - Autonomia (sinais autonômicos) / (autonomic signs)
}

\section{Conclusion}

In the emergency department, an acute headache is a symptom presented by $2 \%-4 \%$ of admitted patients. Secondary headaches are associated with high morbidity and mortality. A need exists for the quick identification of the alarm criteria and a correct stratification of the patient's risk, proper diagnosis and treatment. There are also time constraints in the emergency department. This shows the usefulness of a method for quick identification of the alarm criteria. We believe this is a useful tool for medical education and a clinical aid for clinical practitioners, it may also be a way to educate patients regarding the alarm criteria for emergency headaches.

Keywords: Mnemonic method, Portuguese, Emergency headaches 